\title{
Use of spectral information for red scale pest control
}

\author{
$\square$

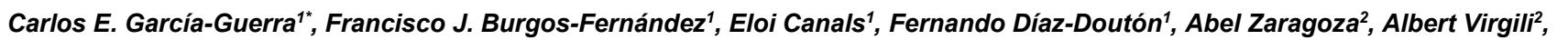

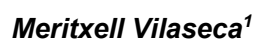

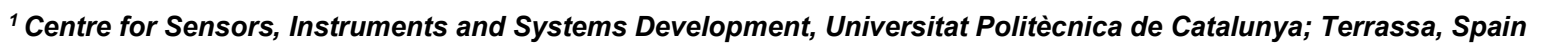

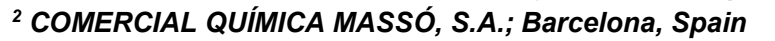

\begin{abstract}

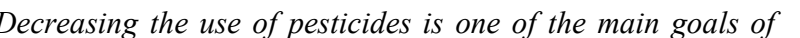

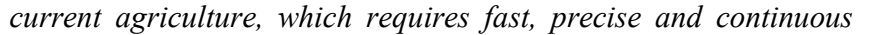

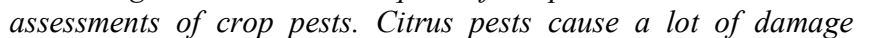

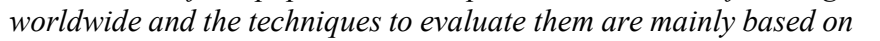

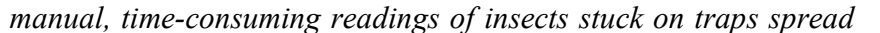

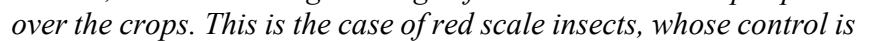

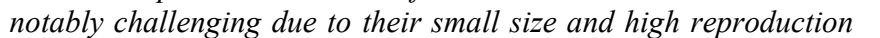

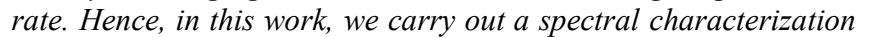

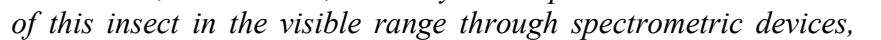

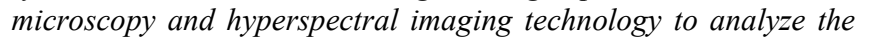
ए

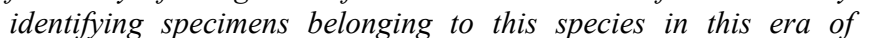

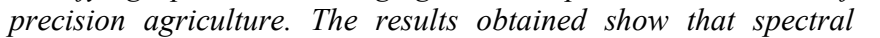

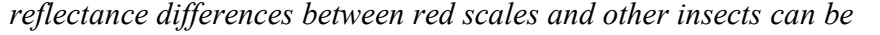

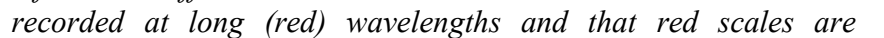

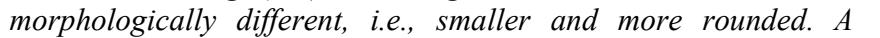

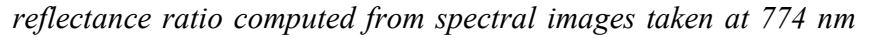

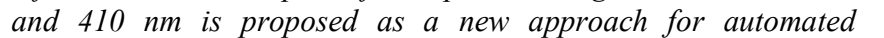

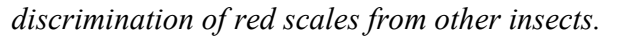

\section{Introduction}

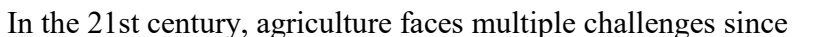

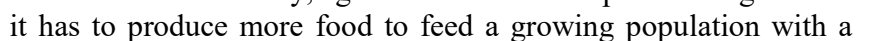

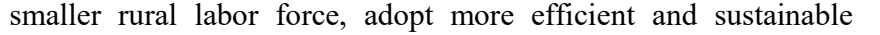

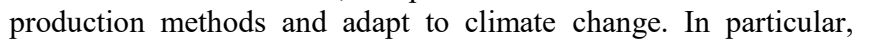

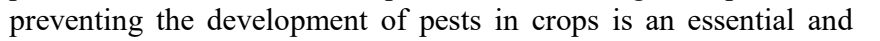

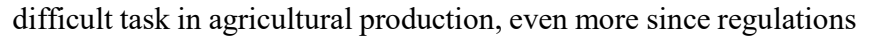

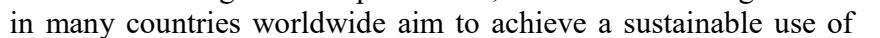

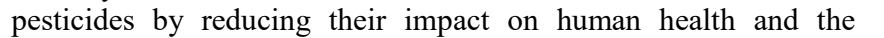

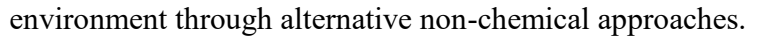

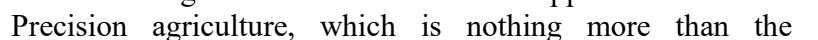

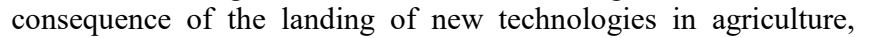

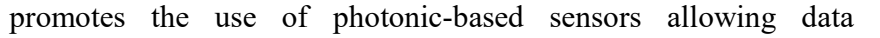

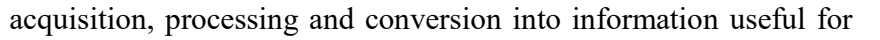

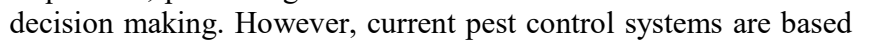

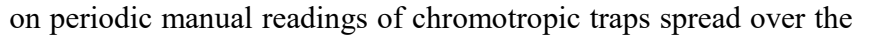

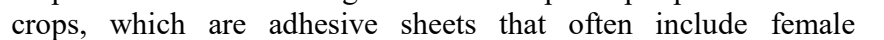

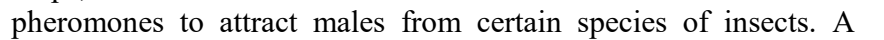

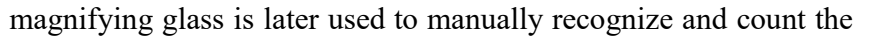

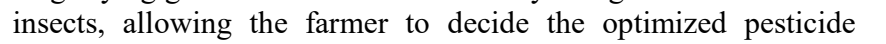

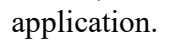

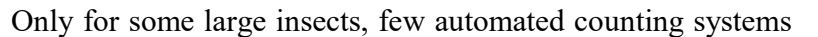

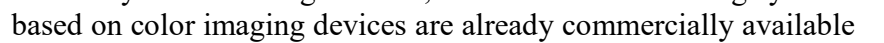

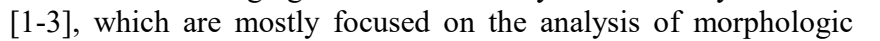

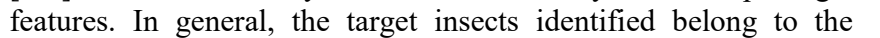

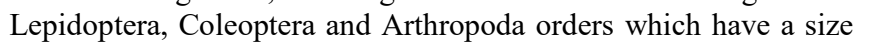

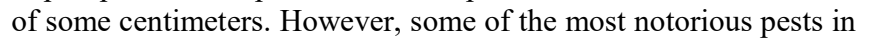

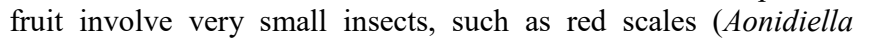

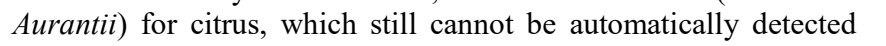

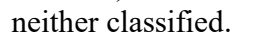

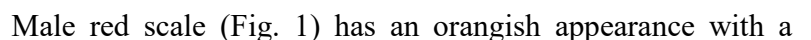

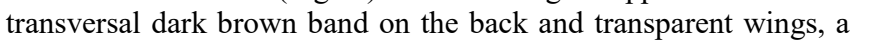

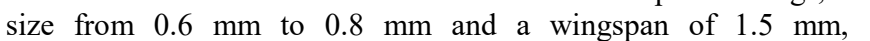

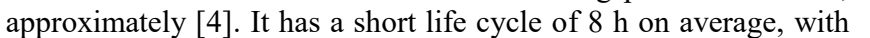
एण

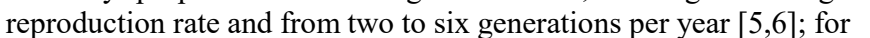
ए एव

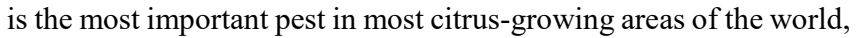

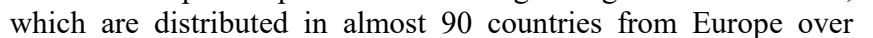

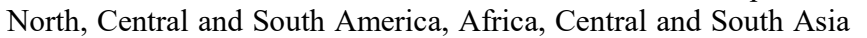

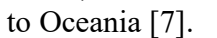

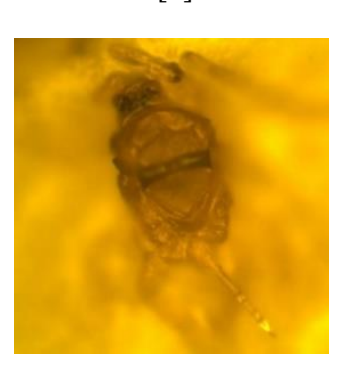

Male red scale on a chromotropic trap. Image captured with an uEye UI-1460-C camera coupled to a Nikon ECLIPSE L150 microscope (magnification: 20x). The wings were out of focus.

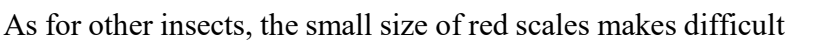

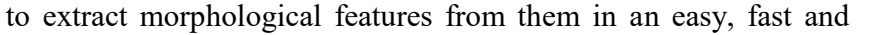

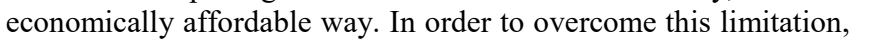

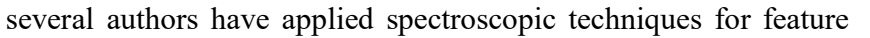

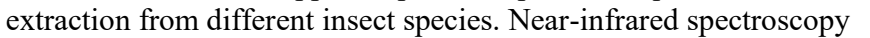

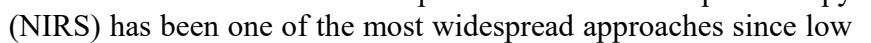

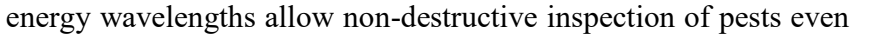

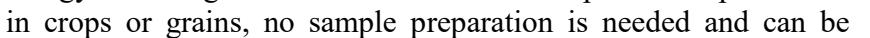

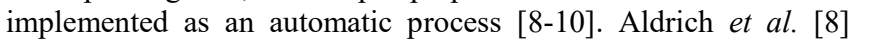

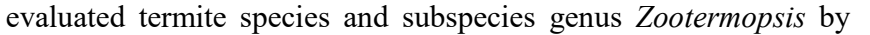

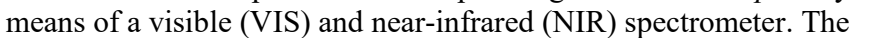

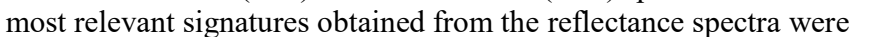

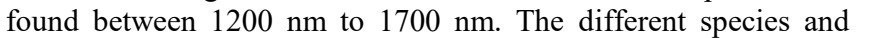

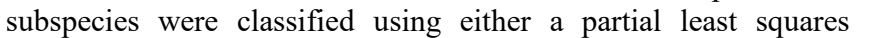

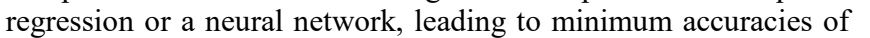

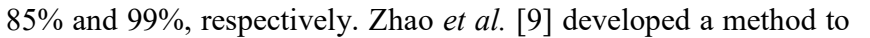

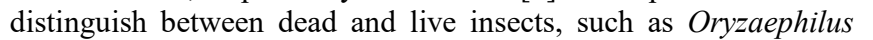

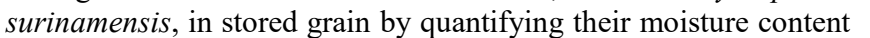

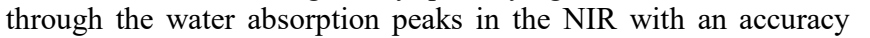

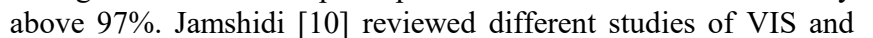

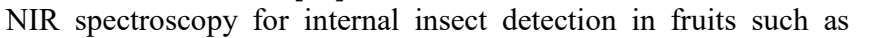

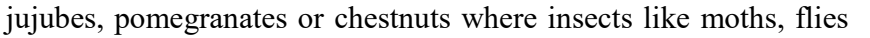

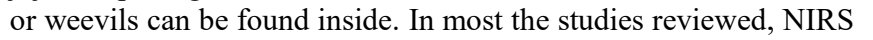

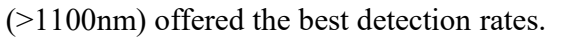

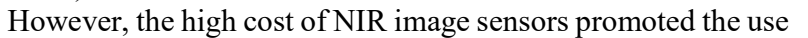

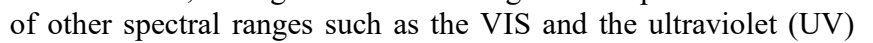




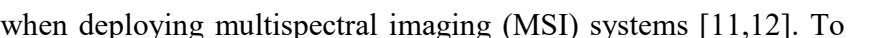

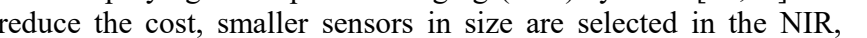

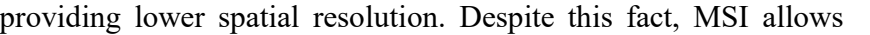

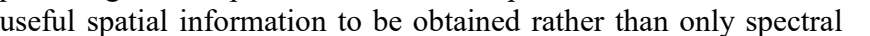

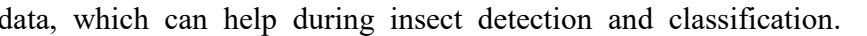

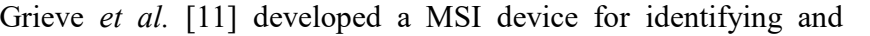

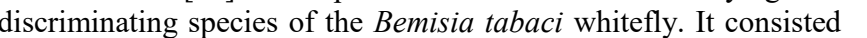

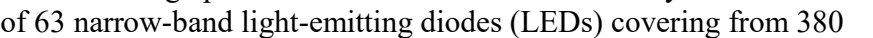
प

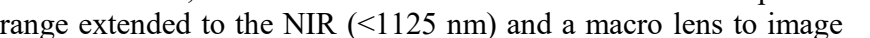

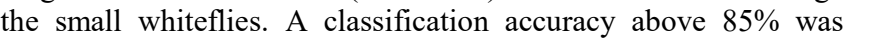

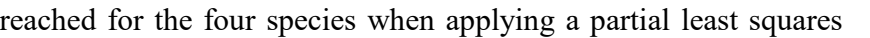

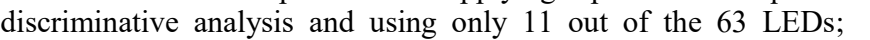

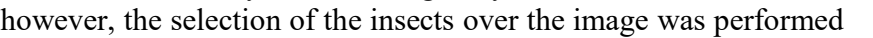

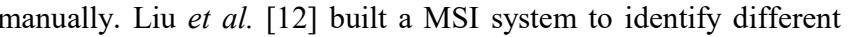

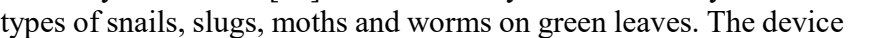

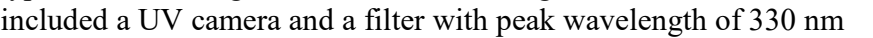

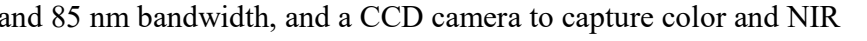

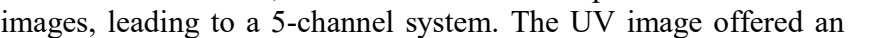

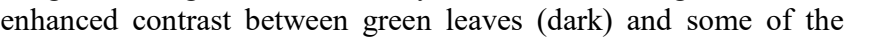

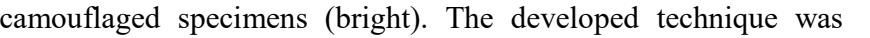

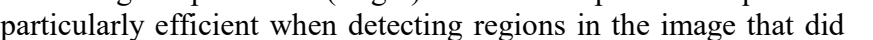

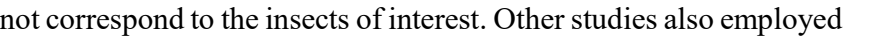

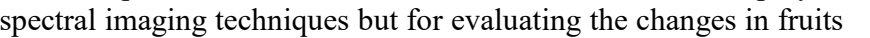

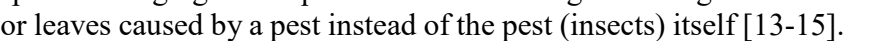

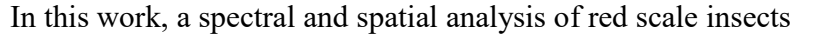

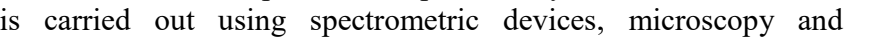

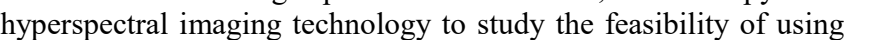

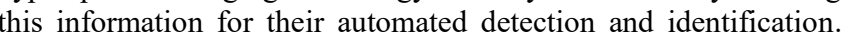

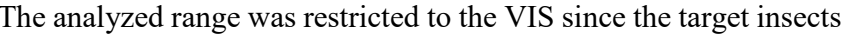

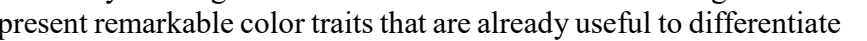

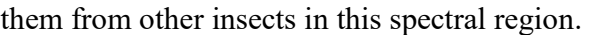

\section{Materials and Methods}

\section{$\square \square \square \square \square \square \square$}

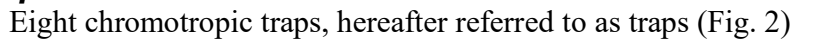

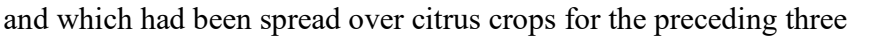

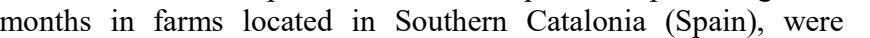

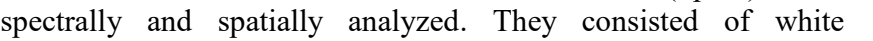

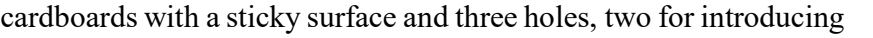

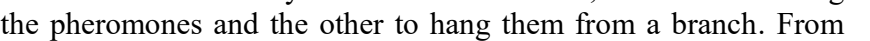

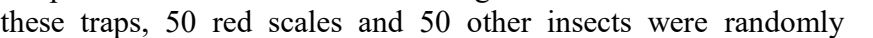

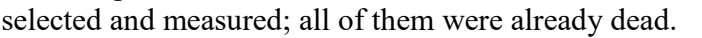

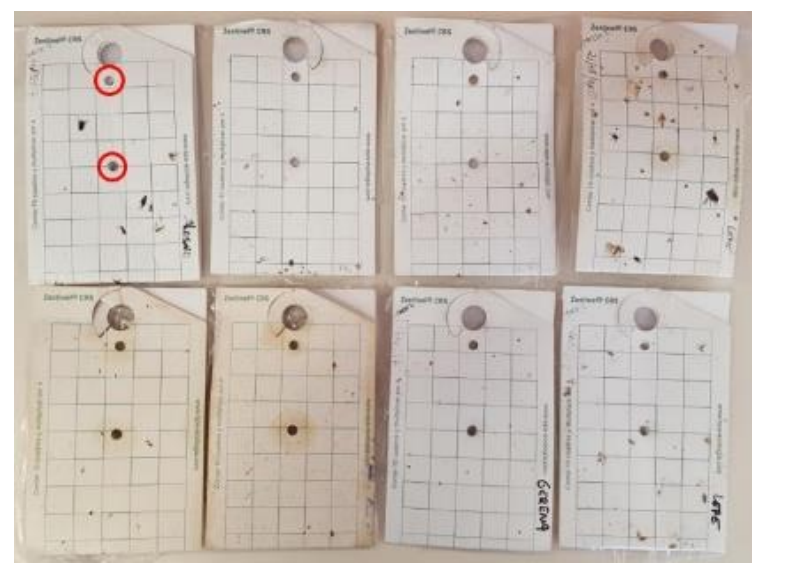

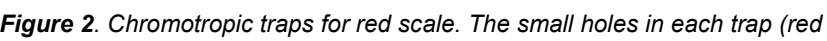
circles) is where the female pheromone is located to attract male red scales.

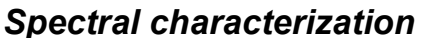

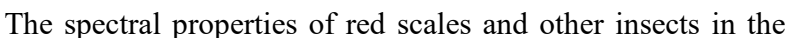

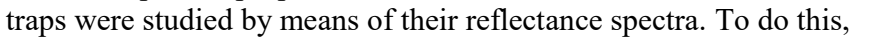

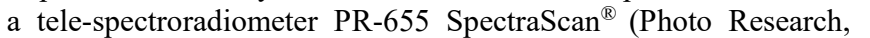

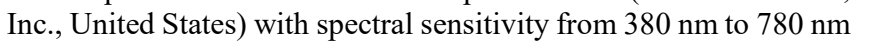

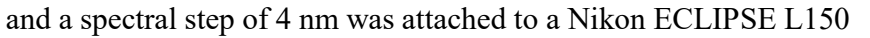

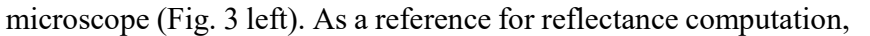

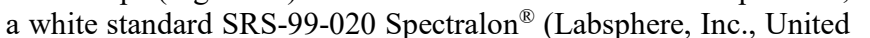

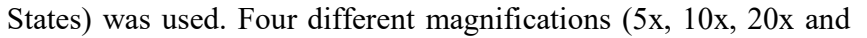

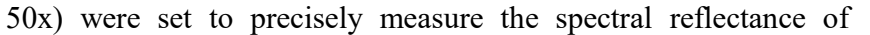

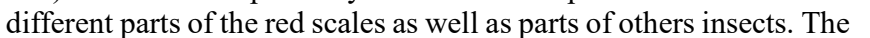

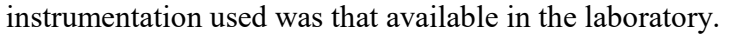
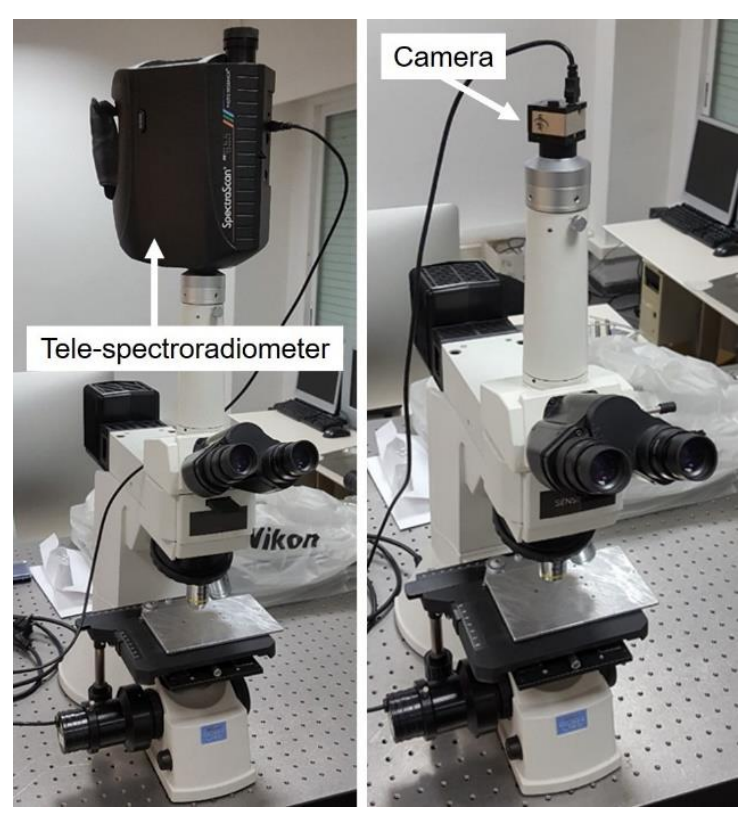

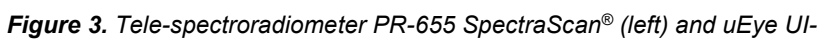
1460-C camera (right) attached to a Nikon ECLIPSE L150 microscope.

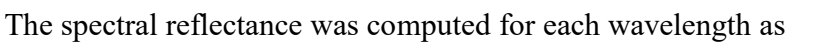
एणाएणाए

$I_{R}=k \cdot \frac{I-I_{D}}{I_{W}-I_{D}}$

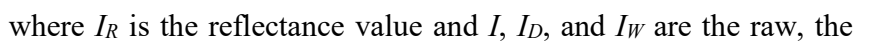

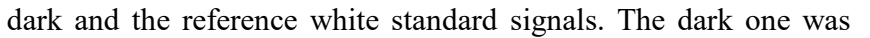

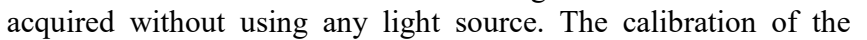

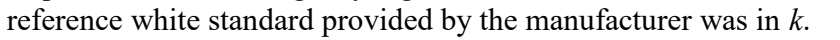

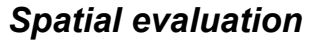

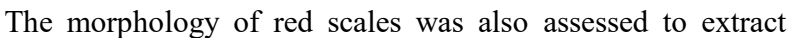

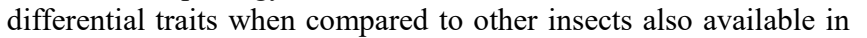
ए

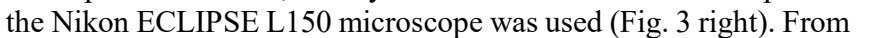
ए

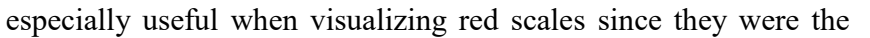

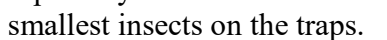

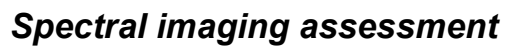

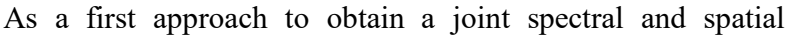

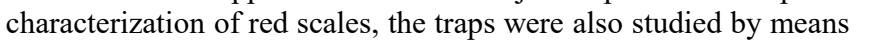




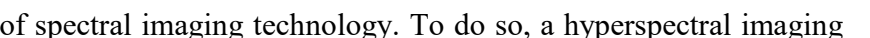

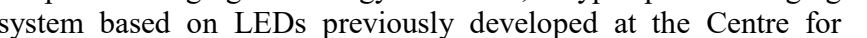

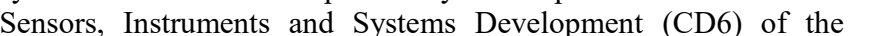

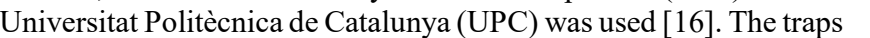

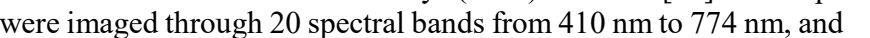

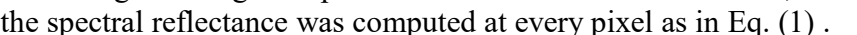

\section{Results and Discussion}

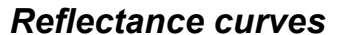

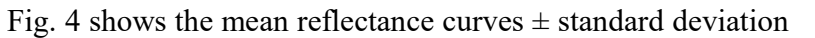

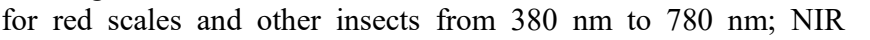

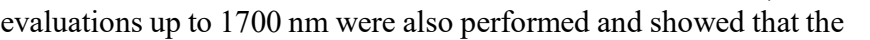
ए एव

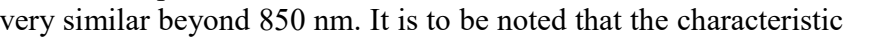

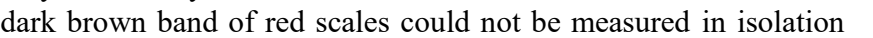

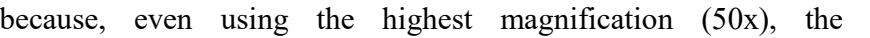

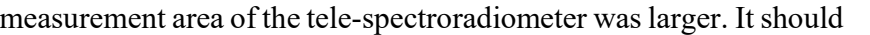

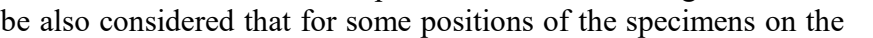

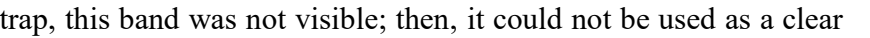
ए

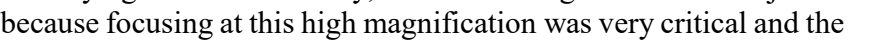

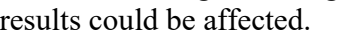

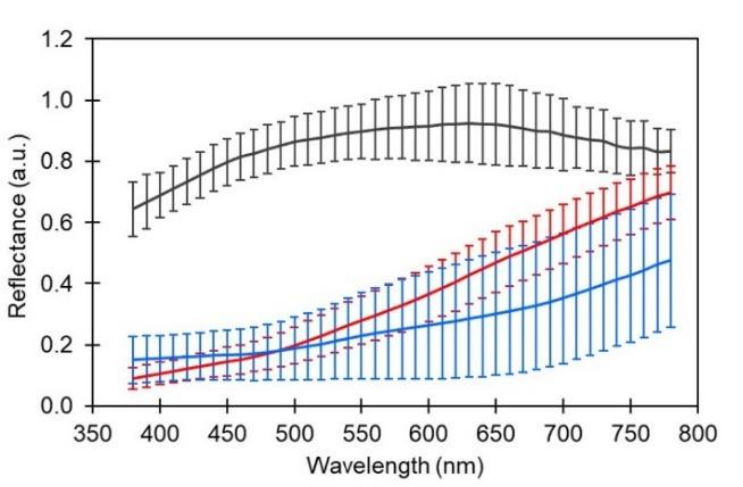

Mean reflectance curves \pm standard deviation of all the 50 red scales (red), 50 other insects (blue) and 40 measurements at the white regions of the traps (gray) at $5 x, 10 x$ and $20 x$.

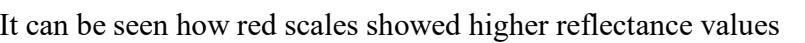

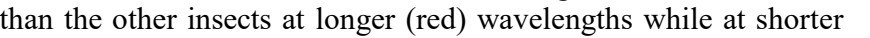

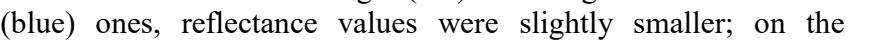

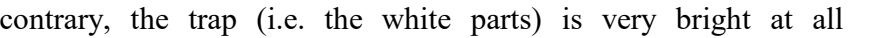

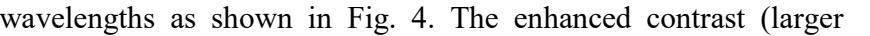

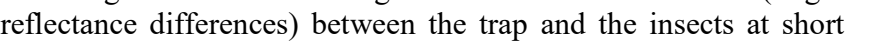

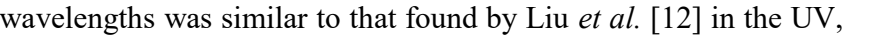

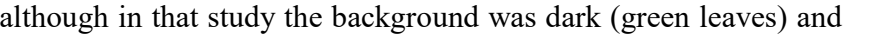

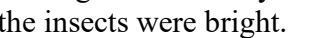

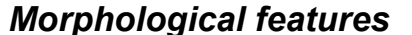

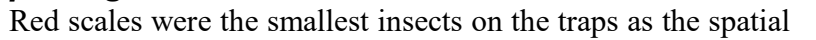

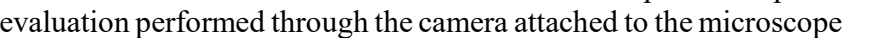

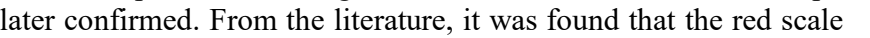

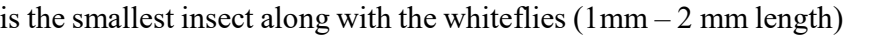

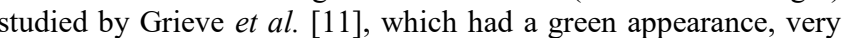

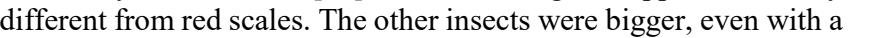

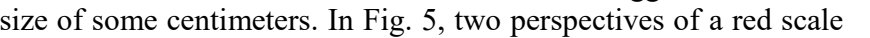

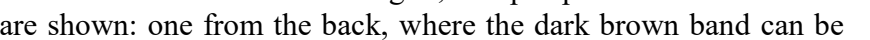

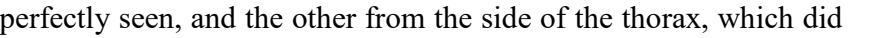

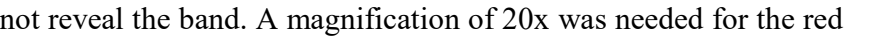

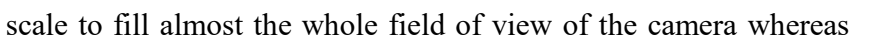

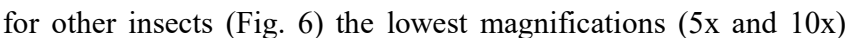

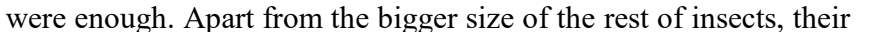

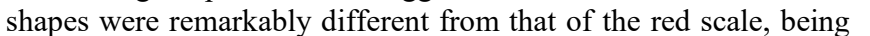

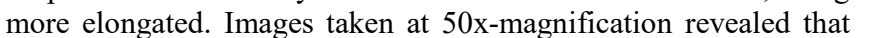

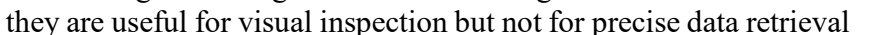

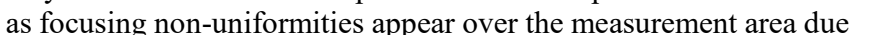

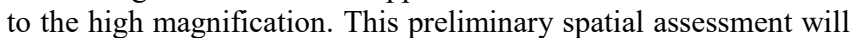

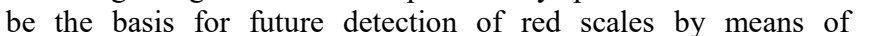

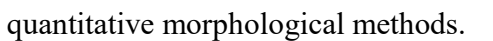
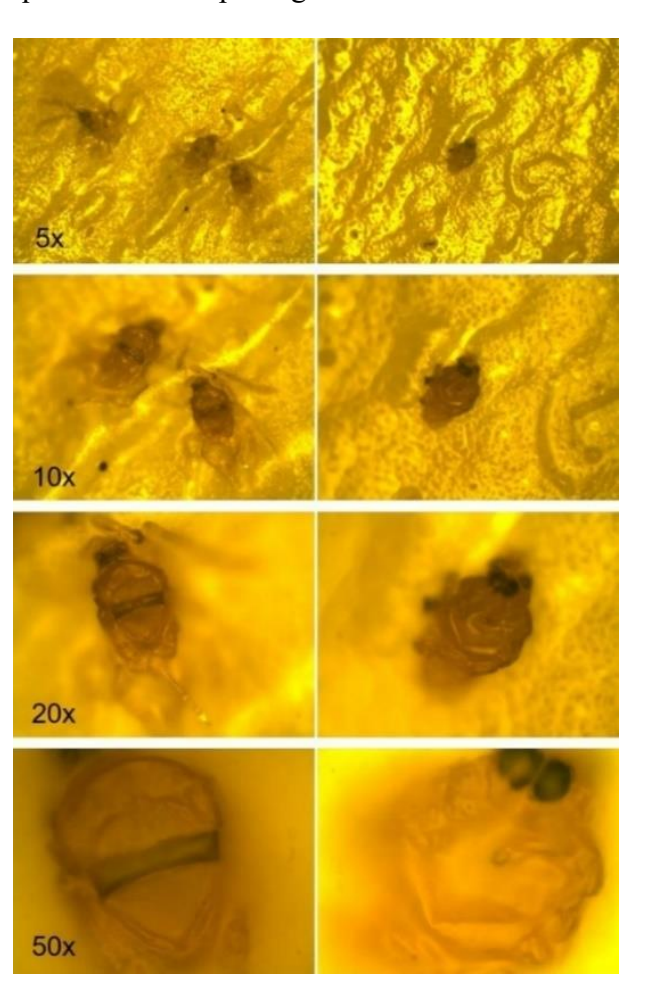

Red scales seen from the back (left) and the thorax (right) at different magnifications. They were captured with an UEye UI-1460-C camera coupled to a Nikon ECLIPSE L150 microscope.

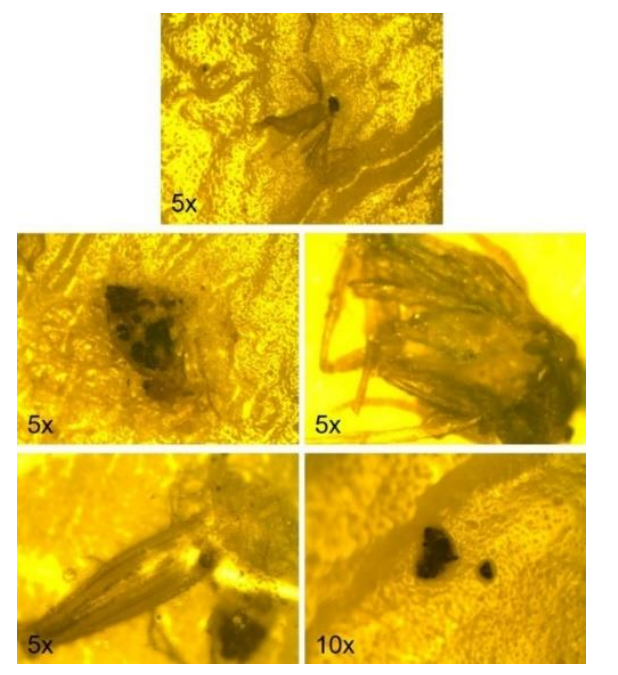

Insects imaged at different magnifications. They were captured with an uEye UI-1460-C camera coupled to a Nikon ECLIPSE L150 microscope. 


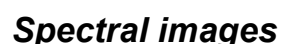

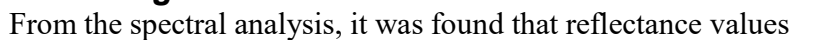

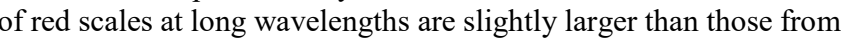

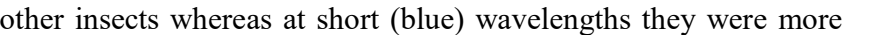

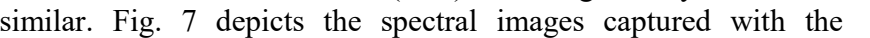

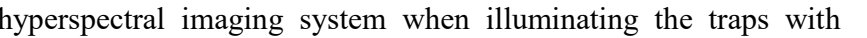

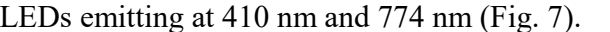
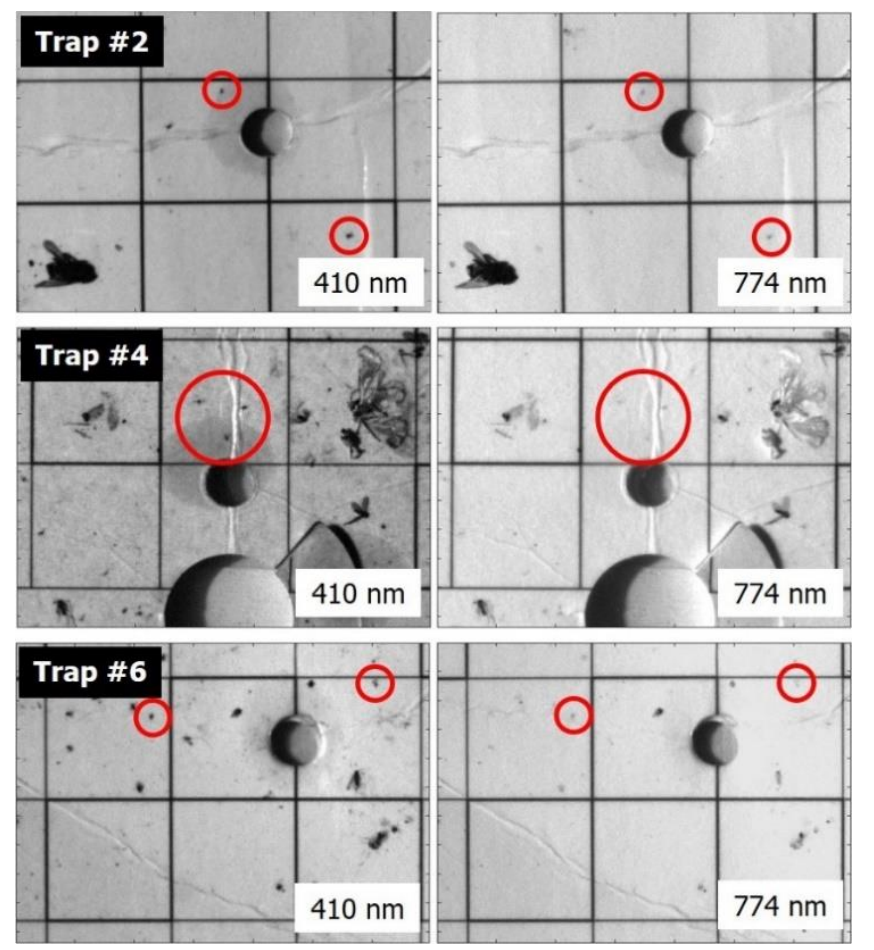

(1) Red circles indicate the location of red scales.

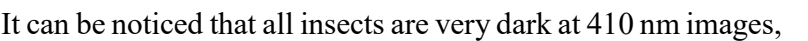

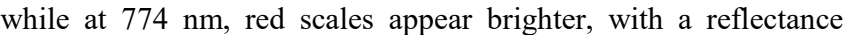
ए

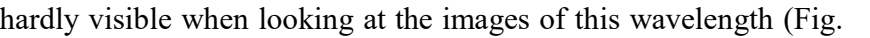

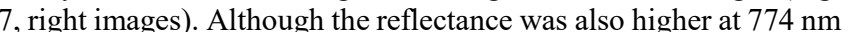

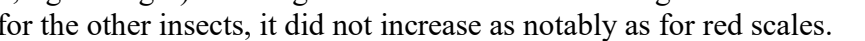

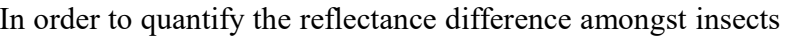

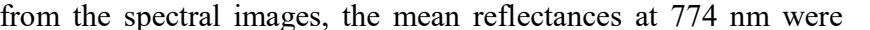

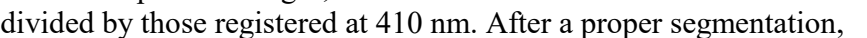

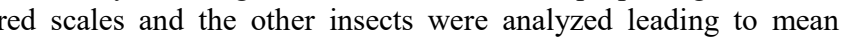
ए

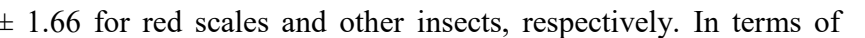

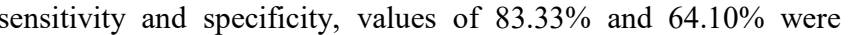

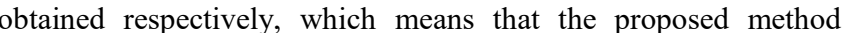

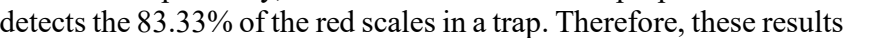

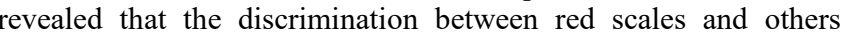

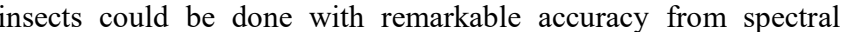

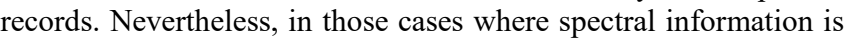

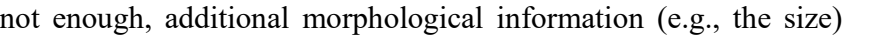

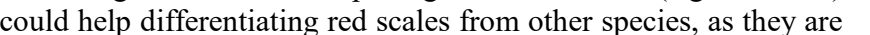

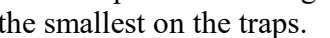

ए

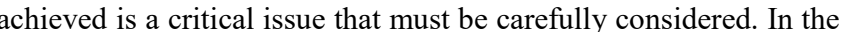

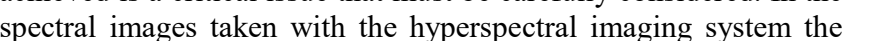

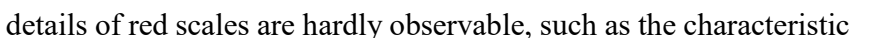

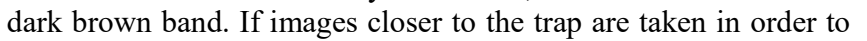

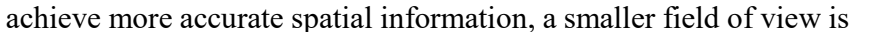

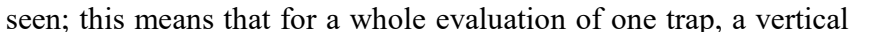

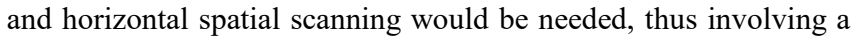

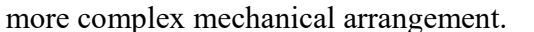

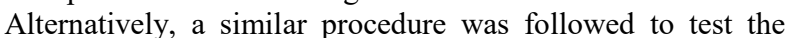

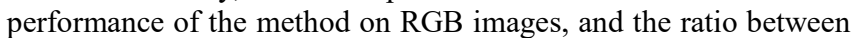
ए

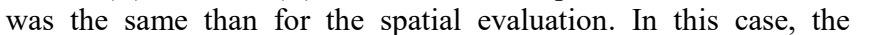

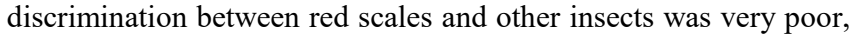

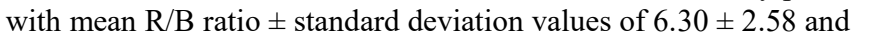

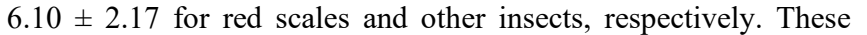
ए

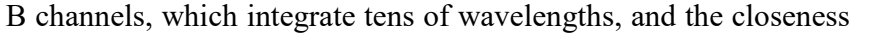

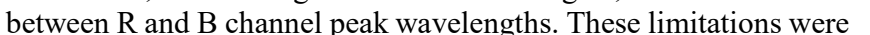

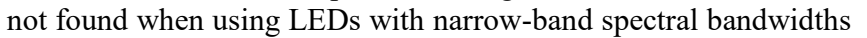

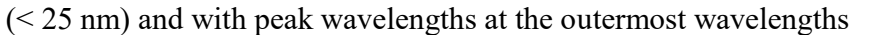

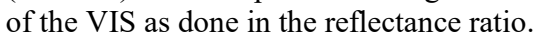

\section{Conclusions}

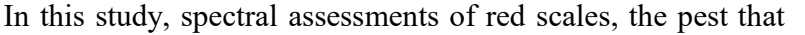

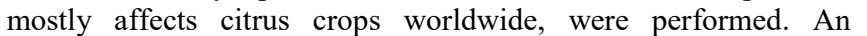

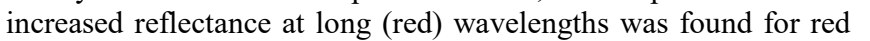

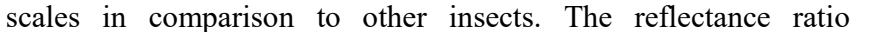

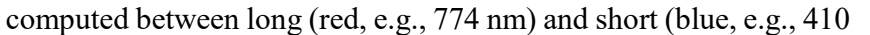

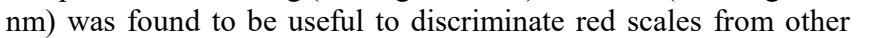

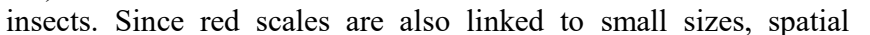

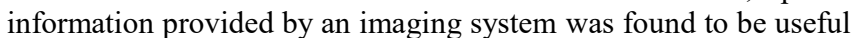

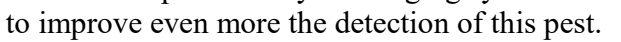

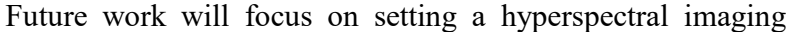

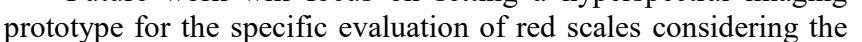

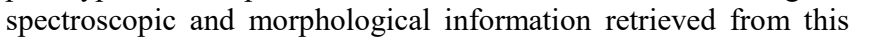

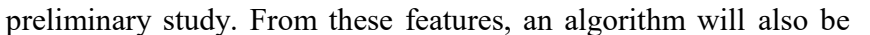

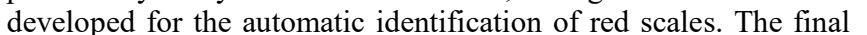

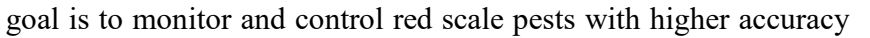

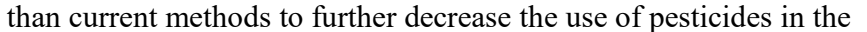

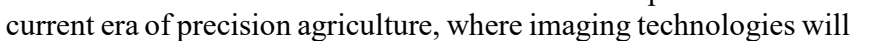

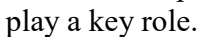

\section{Acknowledgements}

a |

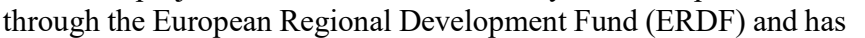
ए

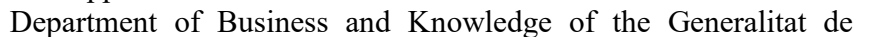

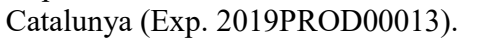

\section{References}

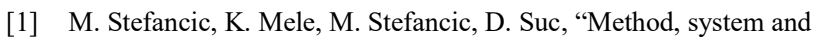

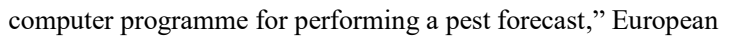

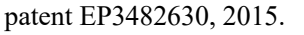

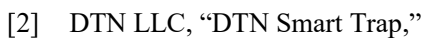

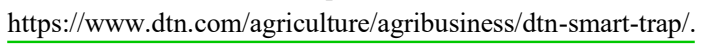

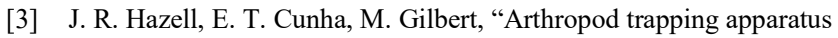

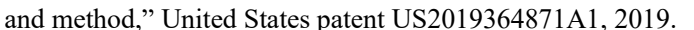

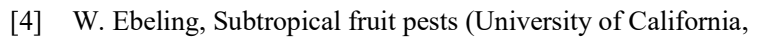

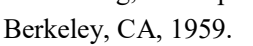




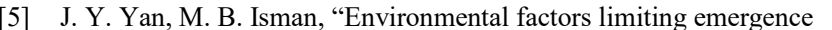

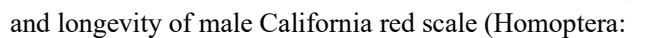

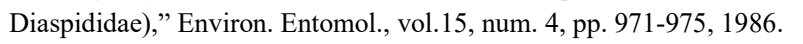

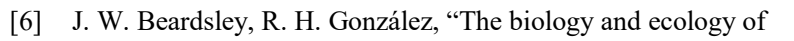

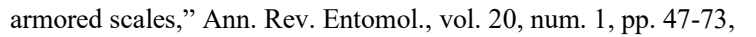
पा1ण

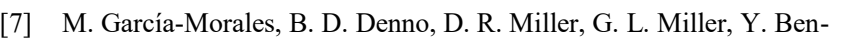

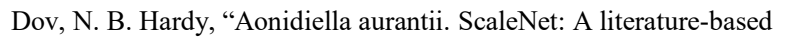
model of scale insect biology and systematics,"

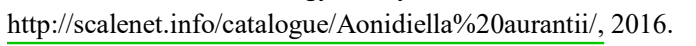

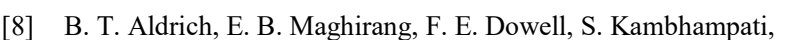

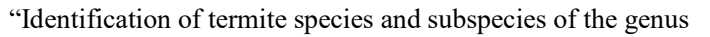

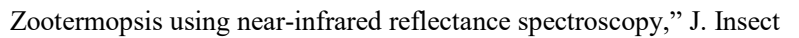

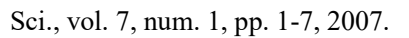

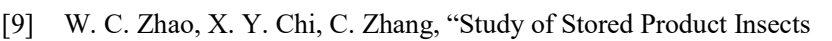

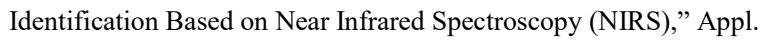

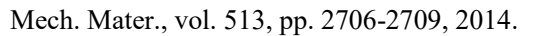

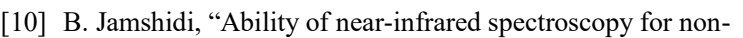

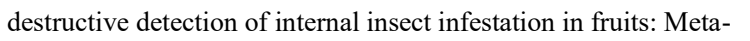

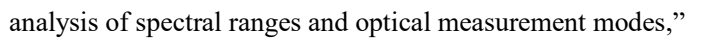

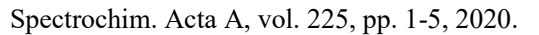

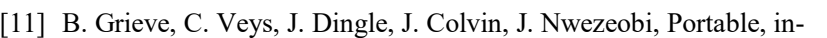

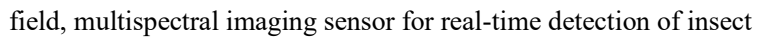

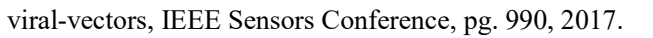

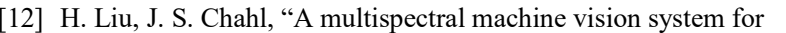

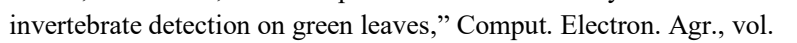

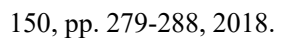

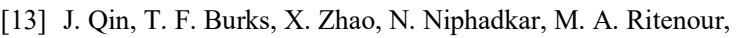

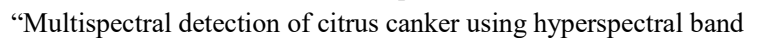

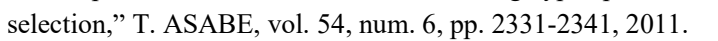

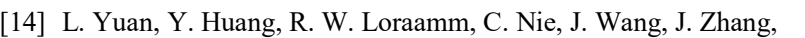
“

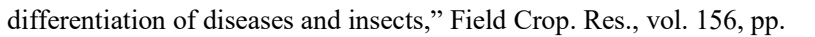
पाणाणापा

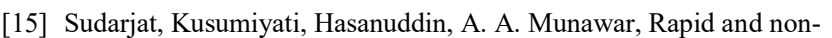

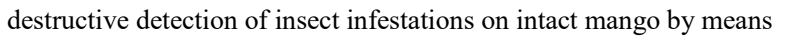

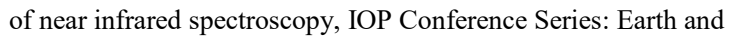

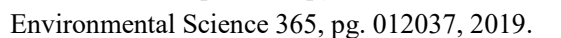

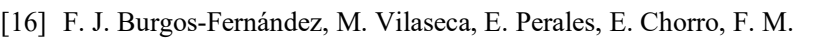

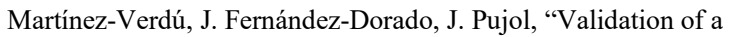

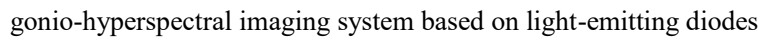

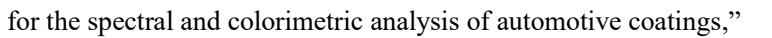

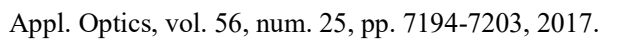

\section{Author Biography}

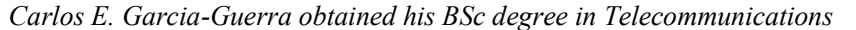

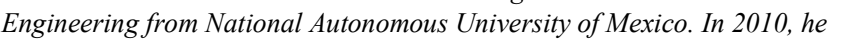

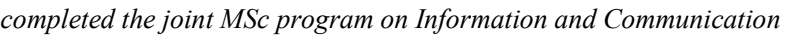

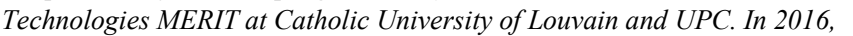

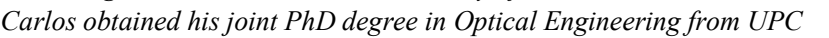

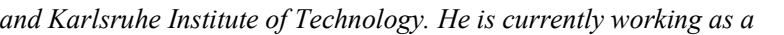

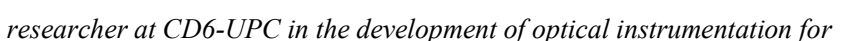

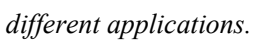

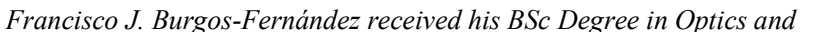

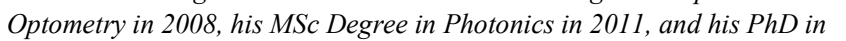

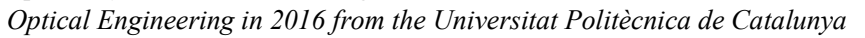
प्र प

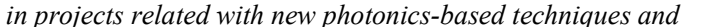

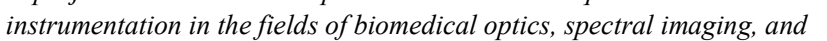
पाणाणाणाणा

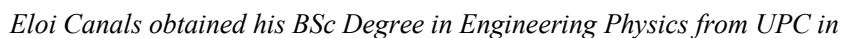

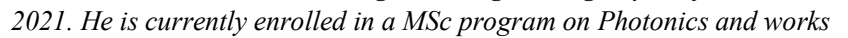
एण

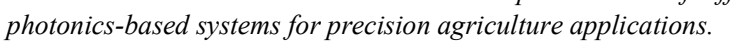

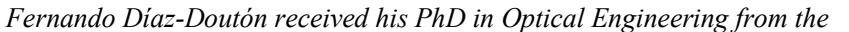

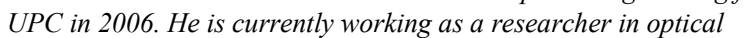

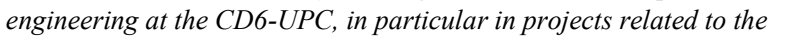

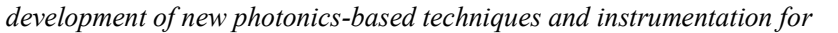

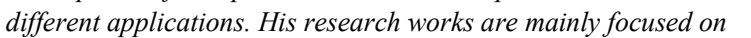

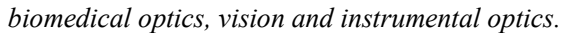

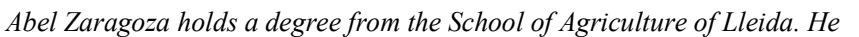

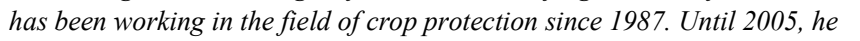

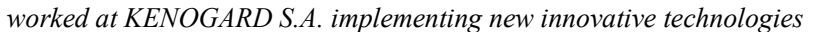

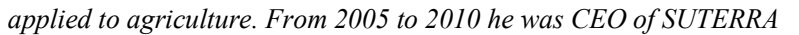

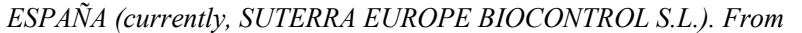
பा

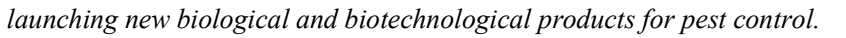

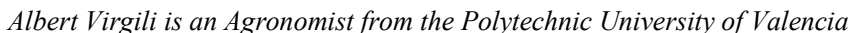

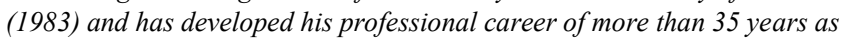

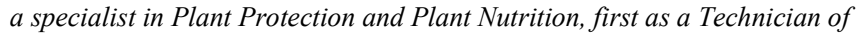

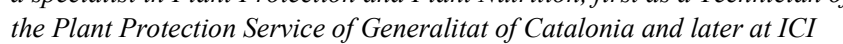

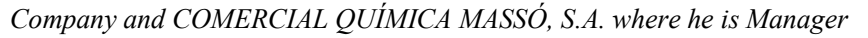

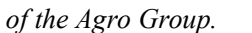

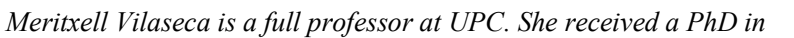

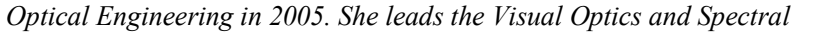

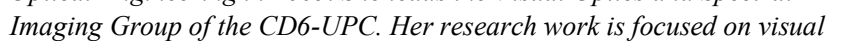

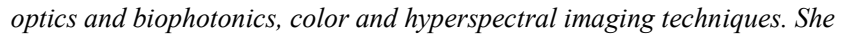

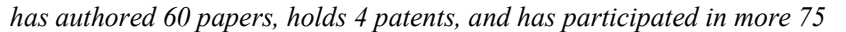

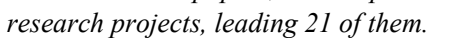

